\title{
CLINICAL CASE REPORT OF A LARGE ANTROCHOANAL POLYP
}

\author{
Cveta Špadijer-Mirkovićl, Aleksandar Perićl, Biserka Vukomanović-Đurđevićz , Ivan Stanojevič́ ${ }^{3}$
}

Department of Otorhinolaryngology, Rhinology Unit ${ }^{1}$, Institute of Pathology ${ }^{2}$, Institute of Medical Research ${ }^{3}$, Faculty of Medicine, Military Medical Academy, Belgrade, Serbia

Summary: Antrochoanal polyps are benign lesions originating from the mucosa of the maxillary sinus. Nasal obstruction and rhinorrhea are their main symptoms. Their endoscopical and radiological appearance makes them relatively easy to diagnose. These polyps are usually presented unilaterally, although bilateral presentation is also possible. We described two cases of atypically giant antrochoanal polyps: in a 15-year-old child and in a 38-year-old man. In both cases, the diagnosis was done by nasal endoscopy and computed tomography (CT) of the paranasal sinuses and supported by histopathological analysis. In the first patient, the excised polyp had the histological characteristic of an angiomatous antrochoanal polyp. Because of their unusual dimension, the combined transoral and endonasal endoscopic approach was performed for complete polyp excision. We discussed the clinical, histopathological and immunohistochemical characteristics of choanal polyps in comparison to inflammatory nasal polyps, and the applicable surgical techniques for treatment of these polyps.

Key words: Antrochoanal polyp; Diagnosis; Chronic rhinosinusitis with nasal polyps; Endoscopic sinus surgery

\section{Introduction}

Inflammatory nasal polyps are in most cases bilateral and they originate usually from anterior or posterior ethmoidal cells, and, less commonly, from maxillary sinus mucosa. In contrary, choanal polyps originate mostly from the maxillary antrum and, rarely, from the sphenoid sinus. Antrochoanal polyps originate from the inner wall of the maxillary sinus and during their growth rarely pass through the natural sinus ostia. Usually, antrochoanal polyps cause a pressure-induced destruction of the medial maxillary sinus wall and formation of an accessory ostium (1).

Killian was the first to describe this disease in detail in 1906 (2). Stammberger found that antrochoanal polyps left the sinus through an accessory ostium in $70 \%$ of the cases (3). Clinical manifestations usually start with unilateral nasal obstruction, although there are reports of cases starting with epistaxis, purulent discharge, polyp strangulation, spontaneous amputation, dyspnoea and dysphagia, obstructive sleep apnoea and rhinophonia (1). Antrochoanal polyps are the most common type of choanal polyps. Other sites of origin may be the sphenoid, ethmoid, (rarely) septum, and inferior turbinate $(4,5)$. These polyps represent $4-6 \%$ of all nasal polyps. However, in children the number can rise up to $33 \%$ $(6,7)$. They are often unilateral but may be bilateral on rare occasions (8). In this report, we present two cases of unusually giant antrochoanal polyps.

\section{Case 1}

A 15-year-old boy was seen at the Department of Otorhinolaryngology with a ten month history of sensation of a foreign body in the throat. Other complaints were right-sided nasal obstruction and intermittent epistaxis, post-nasal discharge, slight headaches and snoring. The patient reported having previously been healthy. Examination by pharyngoscopy revealed a huge polypoid mass hanging from the nasopharynx into the mesopharynx. Upon examination with a nasal speculum, a whitish soft-tissue mass was seen in the right nasal cavity and, upon palpation with a suction tube, the mass was found to be mobile. Nasal endoscopy revealed that the mass arose from the right middle meatus and extended into the nasal cavity and therefore into the nasopharynx, hanging to medial parts of the oropharynx.

Coronal and axial computed tomography (CT) images demonstrated an almost complete opacification of the right maxillary sinus and the presence of a soft-tissue mass passing through an accessory ostium into the posterior part of the nasal cavity and choana (Figure $1 \mathrm{a}, \mathrm{b}, \mathrm{c}$ ).

The patient was taken to the operating theatre under general anaesthesia. On endoscopy, it was confirmed that the mass had originated in the right maxillary sinus. Before removing the intranasal mass, the tip of the inferior portion was grasped with forceps. After separating the intranasal component of the mass, the nasopharyngeal portion was 

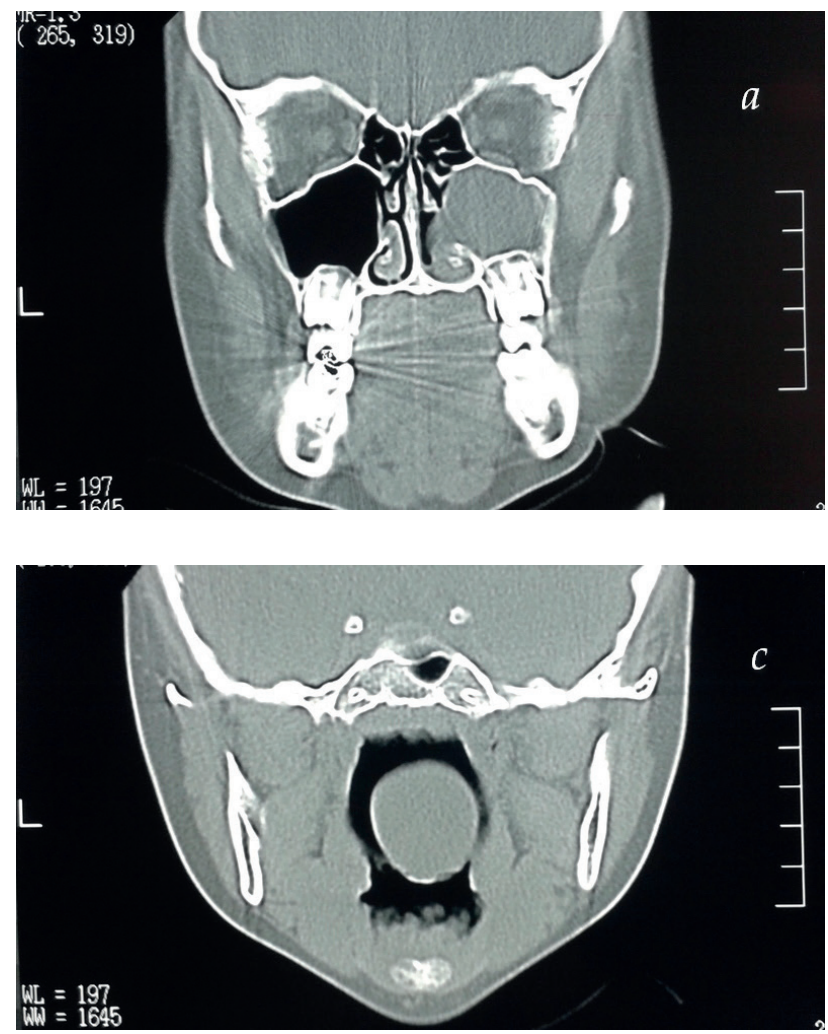

removed via the oral cavity by pulling the silk. This was followed by profuse bleeding, which was controlled by anterior nasal packing. The excised mass was about $12 \mathrm{~cm}$ in length, and with diameter of about $10 \mathrm{~mm}$ (Figure 2). After we removed the nasal pack, the bleeding was significantly decreased. Attention was again focused on the right nasal cavity. The uncinate process was removed and the natural maxillary sinus opening was enlarged with a backbiter. The antrum was found to be filled with the soft-tissue mass, which was of cystic appearance. The antral part was removed with cup forceps. The origin of the polyp was determined to be the posteroinferior antral wall. It was clearly separated from the accessory ostium from which the polyp leaked.

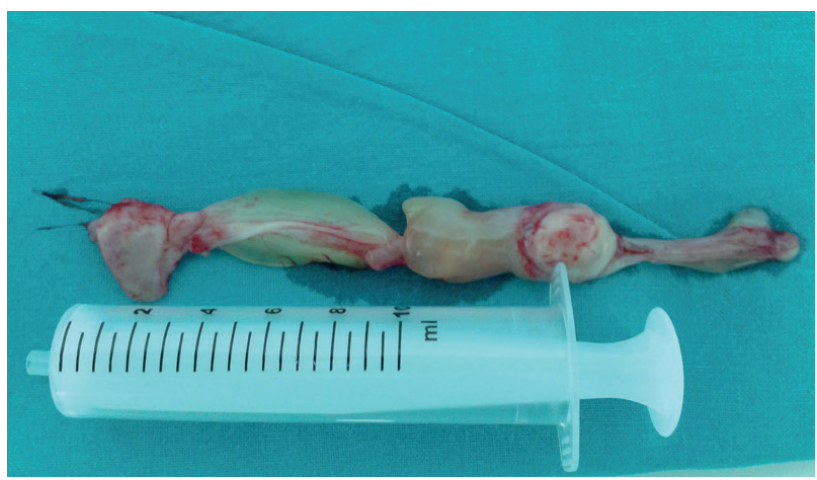

Fig. 2: The excised polyp mass of patient 1.

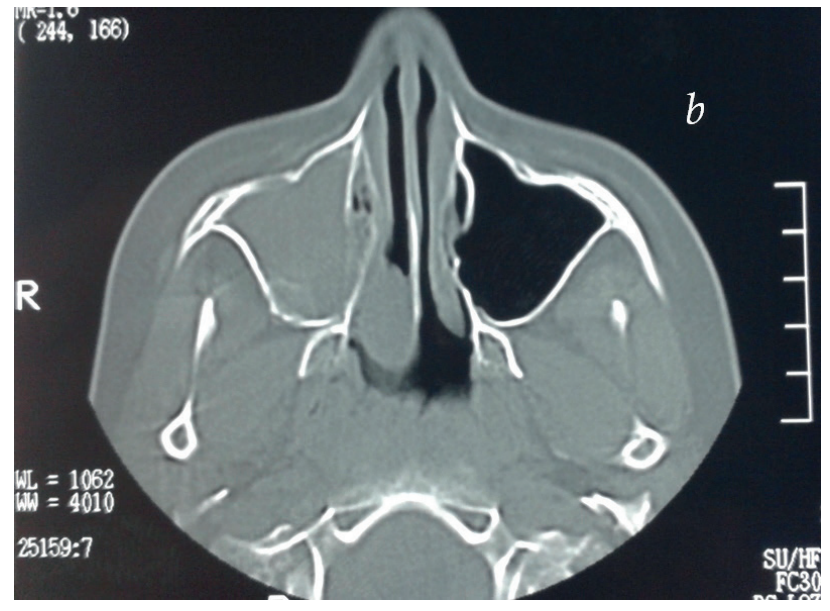

Fig. 1: Coronal (a) and axial (b) CT of the paranasal sinuses showed an almost complete opacification of the right maxillary sinus and the presence of a soft-tissue mass passing through an accessory ostium into the posterior nasal cavity and choana, and, therefore, filling the nasopharynx (c)

Postoperatively, a nasal pack consisting of cotton gauze with antibiotic ointment was removed on the fourth day and the patient was discharged from hospital on the same day. The patient's recovery was satisfactory and he experienced complete relief of his nasal and oral airway obstruction. Histological analysis (Figure 3) supported the diagnosis of antrochoanal polyp. In the nasal part, the polyp was covered by ciliated pseudostratified respiratory epithelium with neutrophil infiltration (a), with periodical areas of metaplastic non-ciliated cuboid epithelium (b). In the nasopharyngeal part, we found the metaplasia of the respiratory epithelium in stratified epithelium of the transitional type (c). We also could see a small number of goblet cells and a paucity of submucous glands. The basement membrane was variably thickened. The bulk of the lesion was represented by edematous subepithelial stroma with a variable degree of inflammation and fibrosis, and with the presence of large blood vessels (d). The inflammatory infiltrate was composed of a mixture of plasma cells, macrophages, lymphocytes and neutrophils (Figure 3 ). The patient remained asymptomatic and disease-free at follow-up 8 months later.

Case 2

The second patient, a 38-year-old man, who was previously operated on twice for nasal polyps, complained of bilateral nasal obstruction, purulent rhinorea, rinolalia and obstructive sleep apnea. These symptoms had been present 

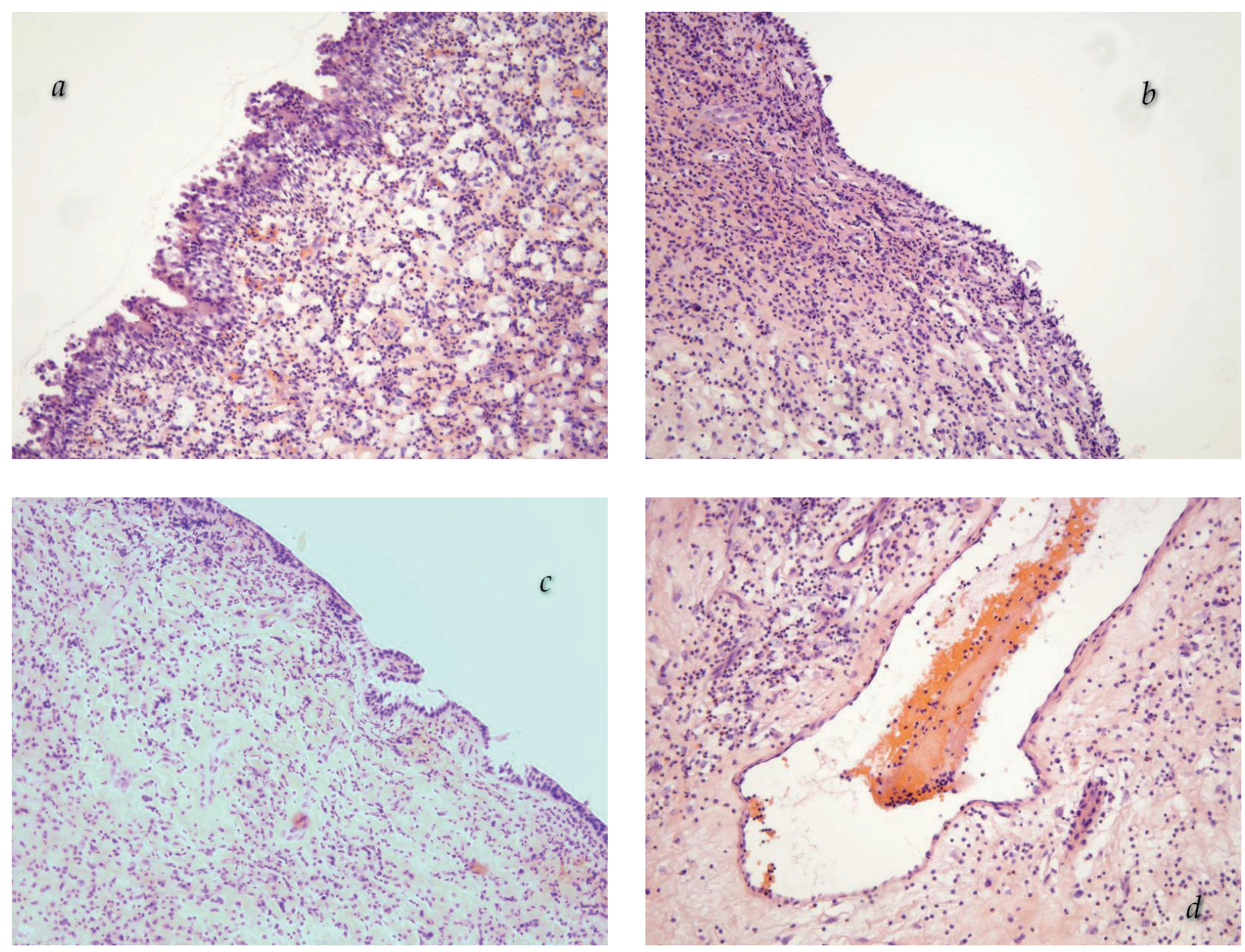

Fig. 3: Microphotographs of excised polyp tissue (patient 1). In the nasal part, the polyp was covered by ciliated pseudostratified respiratory epithelium with neutrophil infiltration (a), with periodical areas of metaplastic non-ciliated cuboid epithelium (b). In the nasopharyngeal part, we found the metaplasia of the respiratory epithelium in stratified epithelium of the transitional type (c). In the polyp stroma, the presence of large blood vessels was found (d). The stromal inflammatory infiltrate is composed of a mixture of macrophages, plasma cells, lymphocytes and neutrophils.

approximately for a year. Examination of the oropharynx revealed a large polypoid mass hanging from the nasopharynx into mesopharynx. On endoscopy, a soft-tissue mass originating from the left middle meatus was seen in the nasal cavity. CT images showed the complete opacification of the left maxillary sinus and a soft-tissue mass filling the low part of the left nasal cavity. We removed the pharyngeal part of the polyp by a transoral approach. It was a large soft-tissue mass with dimensions of $9 \times 8 \mathrm{~cm}$ (Figure 4). The operation was continued using anendoscopic approach. After the uncinectomy and bulectomy, we found the polyp stalk arising from the inner wall of the left maxillary sinus, near by the posterior margin of the accessory ostium. Therefore, we found that both the natural and accessory ostium were obstructed by the polyp mass. After we removed the lesion, we found the maxillary sinus cavity was filled by compact mucus. The natural maxillary sinus ostium was enlarged with a backbiter. The mucus from the maxillary antrum was aspirated and sent for microbiological analysis. The bacteriological strains isolated from the antrum included Staphylococcus aureus and Haemophilus influenzae. After the surgery, the patient was treated with amoxicillin-clavulanate (in a dose of $1000 \mathrm{mg}$, two times per day) for seven days. The patient's recovery was satisfactory and he experienced complete relief of his airway obstruction. It was verified that the excised mass was an antrochoanal polyp. On pathohistological examination, no large blood vessels were found in the polyp stroma. The patient remained asymptomatic and disease-free at follow-up 6 months later.

\section{Discussion}

Macroscopically, the antrochoanal polyp is usually composed of a cystic part filling the maxillary sinus and a solid 


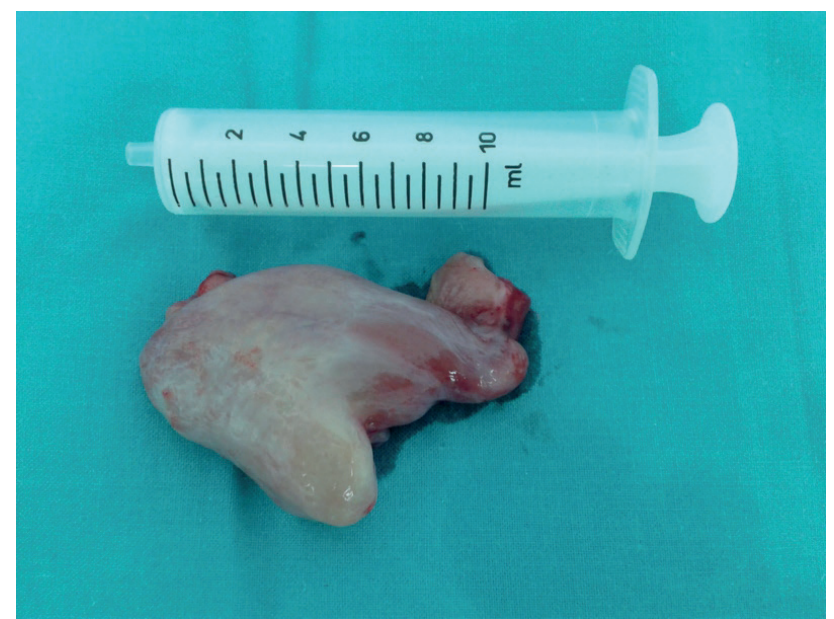

Fig. 4: The excised polyp mass of patient 2.

part coming out through the natural or accessory maxillary ostium into the middle meatus and hence to the choana. Some authors suggest that antrochoanal polyps may actually represent expanding cysts that eventually protrude into the nasal cavity (9). However, in our second patient, we found no cystic formation within the affected maxillary antrum. Choanal polyps show some histological differences when compared with bilateral inflammatory polyps. Inflammatory infiltrate of choanal polyps is composed of a high number of macrophages, neutrophils and lymphocytes, and a low number of eosinophils. Therefore, the rare presence of epithelial goblet cells and submucous glands is characteristic of choanal polyps (10). The antral portion of the antrochoanal polyps may also be characterized by the presence of cysts in the lamina propria (9). In our patients' polyps, we found no stromal microcysts in their endosinusal segments. In our first patient, one of the symptoms was unilateral epistaxis. Histologically, his polyp showed a highly vascular stroma with multiple dilated blood vessels. These histological findings were verified as angiomatous antrochoanal polyps (11).

The tissue of choanal polyps has a different inflammatory mediator profile in comparison to inflammatory nasal polyps. In contrast to nasal polyposis, choanal polyps lack eosinophils. Corresponding to this, Rudack et al. (12) did not detect elevated interleukin-5 (IL-5) protein concentrations in tissue homogenates of antrochoanal polyps but a significantly increased level of IL-6 compared to control mucosa of the inferior turbinate. This different mediator profile is maybe associated with the different level of protective mucosal mechanisms against bacterial colonisation and infection. Preliminary results presented by Mladina et al. (13) showed that signs of the presence of bacterial biofilm were found in all patients with nasal polyposis. In cases with antrochoanal polyps, biofilm formation was found in the stalk and nasal part of the antrochoanal polyps, whereas there were no signs of biofilm on the diseased mucosa of the antral part. These findings are in accordance with the results of a study conducted by Honkanen et al. (14). They found a higher level of epithelial and leucocyte expression of indoleamine 2,3-dioxigenase (IDO), an intracellular enzyme with strong antimicrobial activity, in tissue specimens of inflammatory nasal polyps than in antrochoanal polyp tissue. One of the main characteristics of antrochoanal polyps is the tendency for rapid growth, resulting in their impressive dimensions. Mahfouz et al. (15) showed that the expression of basic fibroblast growth factor (bFGF) and transforming growth factor beta (TGF- $\beta$ ) was significantly higher in tissue of antrochoanal polyps than in nasal polyposis and healthy mucosa. Increased expression of bFGF was detected in fibroblasts, blood vessel endothelial cells, basement membrane, basal epithelial cells, and inflammatory cells. Therefore, antrochoanal polyps may represent an inflammatory reaction caused by overproduction of tissue-derived growth factors in an inductive environment.

Differential diagnosis includes other masses that have a maxillary antral component such as: mucocele, inverted papilloma, allergic fungal rhinosinusitis, or other sinonasal polyps. Other less frequent differential diagnosis are adenoid hypertrophy, posterior tip inferior turbinate hypertrophy, Tornwaldt's cysts and angiofibroma. Bone destroying diseases such as lymphoma, Wegener granulomatosis or rhabdomyosarcoma should also be considered. The treatment of antrochoanal polyps is almost always surgical. Sometimes, antrochoanal polyps regress with medication. Seshadri (16) reported a case of antrochoanal polyp treated with intranasal steroids. No recurrence was noted one year following the initial diagnosis (16). The original method of treating by simple polypectomy without involving the sinus results in long-term failure. This technique has a high rate of recurrence due to insufficient resection of the intramaxillary portion of the polyp (17). Our second patient had previously two incomplete excision of an antrochoanal polyp with postoperative relapse of the disease. Thus, the treatment of choice is complete removal of both the antral and choanal parts of the polyp. There is controversy concerning the route of removal of the antral part of the polyp. The transcanine approach offers good exposure for complete removal of the antral part (17). However, this procedure may have possible complications, including cheek anaesthesia, cheek swelling and injury of the infraorbital nerve, and it carries the risk of damaging the growing teeth and the growth centers of the maxilla (18). Endoscopic sinus surgery has recently been shown to be a safe and effective method for treating antrochoanal polyps. It consists of resection of the nasal part of the polyp and the cystic antral part with attachment to the maxillary wall via the middle meatus (19). Lee and Huang (20) used the transnasal endoscopic approach for antrochoanal polyps originating from the inferior and posterior walls of the maxillary sinus and the combined endoscopic and transcanine approach for polyps originating from the lateral walls of the maxillary sinus. In our cases, after separating the intranasal component of the mass, the pharyngeal portion of the polyp was removed via the oral cavity by pulling the silk. Therefore, in cases of giant antrochoanal polyps, this 
endoscopic excision of the antral and intranasal portion of the polyp should be associated with a trans-oral approach.

\section{Conclusion}

In this paper, we described two cases of large antrochoanal polyps. In the first case, the presence of highly vascular stroma with multiple dilated blood vessels was referred to as a rare angiomatous antrochoanal polyp. In cases of giant antrochoanal polyps, the endoscopic approach should be associated with trans-oral polyp excision.

\section{References}

1. Maldonado M, Martínez A, Alobid I, Mullol J. The antrochoanal polyp. Rhinology 2004; 43: 178-82

2. Killian G. The origin of antrachoanal polyp. Lancet 1906; 2: 81-2.

3. Stammberger H, Hawke M. Essentials of functional endoscopic sinus surgery. Mosby, St Louis 1993, pp. 103-5.

4. Lopatin A, Bykova V, Piskunov G. Choanal polyps: one entity, one surgical approach? Rhinology 1997; 35: 79-83.

5. Aydin O, Keskin G, Ustündağ E, Işeri M, Ozkarakaş H. Choanal polyps: an evaluation of 53 cases. Am J Rhinol 2007; 21: 164-8.

6. Orvidas LJ, Beatty CW, Weaver AL. Antrochoanal polyps in children. Am J Rhinol 2001; $15: 321-5$.

7. Segal N, Gluk O, Puterman M. Nasal polyps in the pediatric population. B-ENT 2012; 8: 265-7.

\section{Corresponding author:}

Cveta Špadijer-Mirković, MD, Department of Otorhinolaryngology, Rhinology Unit, Faculty of Medicine, Military Medical Academy, Crnotravska 17, 11040,Belgrade, Serbia; e-mail: cecaspadijermirkovic@gmail.com
8. Yilmaz YF, Titiz A, Ozcan M, Tezer MS, Ozlugedik S, Unal A. Bilateral antrochoanal polyps in an adult: a case report. B-ENT 2007; 3: 97-9.

9. Arbo RJ, Torres FX, Gomez J. Nasal cavity and paranasal sinuses. In: Pilch BZ (ed.) Head and neck surgical pathology. Philadelphia: Lippincott Williams \& Wilkins 2001, pp. 86-7.

10. Składzień J, Litwin JA, Nowogrodzka-Zagórska M, Wierzchowski W. Morphological and characteristics of antrochoanal polyps: comparison with chronic inflammation-associated polyps of the maxillary sinus. Auris Nasus Larynx 2001; 28: $137-41$.

11. Sayed RH, Abu-Dief EE. Does antrochoanal polyp present with epistaxis? J Laryngol Otol 2010; 124: 505-9.

12. Rudack C, Stoll W, Bachert C. Cytokines in nasal polyposis, acute and chronic sinusitis. Am J Rhinol 1998; 12: 383-8.

13. Mladina R, Poje G, Vuković K, Ristić M, Musić S. Biofilm in nasal polyps. Rhinology 2008; 46: 302-7.

14. Honkanen T, Luukkainen A, Lehtonen M, Paavonen T, Karjalainen J, Hurme M, et al. Indoleamine 2,3-dioxygenase expression is associated with chronic rhinosinusitis with nasal polyps and antrochoanal polyps. Rhinology 2011; 49: 356-63.

15. Mahfouz ME, Elsheikh MN, Ghoname NF. Molecular profile of the antrochoanal polyp: up-regulation of basic fibroblast growth factor and transforming growth factor beta in maxillary sinus mucosa. Am J Rhinol 2006; 20: 466-70.

16. Seshadri R. Antrochoanal polyp: a case report of treatment with intranasal steroids. J Laryngol Otol 1995; 109: 553-4. yps. J Laryngol Otol 1994; 108: 1055-7.

18. Yaman H, Yilmaz S, Karali E, Guclu E, Ozturk O. Evaluation and management of antrochoanal polyps. Clin Exp Otorhinolaryngol 2010; 3: 110-4.

19. Ozer F, Ozer C, Cagici CA, Canbolat T, Yilmazer C, Akkuzu B. Surgical approaches for antrochoanal polyp: a comparative analysis. B-ENT 2008; 4: 93-9.

20. Lee TJ, Huang SF. Endoscopic sinus surgery for antrochoanal polyps in children. Otolaryngol Head Neck Surg 2006; 135: 688-92.

Received: $25 / 03 / 2014$

Accepted in revised form: 23/06/2014
17. El-Guindy A, Mansour MH. The role of transcanine surgery in antrochoanal pol- 